Gut, 1985, 26, 481-484

\title{
Conservative treatment of gastrointestinal haemorrhage
}

\author{
S B ROFE, J M DUGGAN, E R SMITH, AND C J THURSBY \\ From the Gastroenterology Unit, The Royal Newcastle Hospital, Newcastle, Australia
}

SUmmary The Gastroenterology Unit of the Royal Newcastle Hospital treats all acute bleeders in the hospital and has followed a policy of conservative blood transfusion and early surgery directed to gastric ulcer upon rebleeding. A prospective study of 201 consecutive episodes is presented and compared with recent series treated more conventionally. Our patients were transfused less, and operated upon less often with a lower mortality rate in those with chronic peptic ulcers. The data suggest that a reversion to the less aggressive treatment policies of several decades ago, combined with early limited surgery directed to endoscopically proven gastric ulcer is worthy of trial.

Acute upper gastrointestinal haemorrhage remains a serious clinical problem with a high mortality rate. Whether or not the modern means of diagnosis and treatment have lowered the mortality rate is uncertain with no clear evidence of benefit from any treatment. ${ }^{1}$ The debate has recently been reopened by the large series from Nottingham showing no evidence of benefit from endoscopy or early surgery. ${ }^{2}{ }^{3}$ As a previous study ${ }^{4}$ suggested no definite benefit from an aggressive surgical policy and a subsequent study ${ }^{5}$ delineated the high risk groups the Gastroenterology Unit of the Royal Newcastle Hospital has pursued a policy of conservative blood transfusion and early limited surgery.

\section{Methods}

\section{PATIENTS}

The study group consists of the 201 consecutive admissions to the unit for the 12 months from March 1980 for acute upper gastrointestinal bleeding; 21 were referred from other hospitals and 20 patients were already hospitalised when they bled. Since 1974, all patients with acute upper gastrointestinal bleeding have been admitted directly to the Gastrointestinal Unit for joint management by a physician and surgeon associated with the Unit. All patients actively bleeding or shocked were admitted to the intensive care unit for joint management with the intensive care team. All patients had a peripheral intravenous line inserted and were cross matched.

Address for correspondence: Dr J M Duggan, Gastroenterology Unit, York Wing. Royal Newcastle Hospital, Newcastle. NSW 2300, Australia.

Received for publication 9 July 1984
Broadly, the indications for blood transfusion were those of Ivy et al. ${ }^{6}$ 'The best and simplest physiologic and clinical symptom of the need for blood after haemorrhage is dizziness or faintness on sitting up'. In practice, a fall of $20 \mathrm{mmHg}$ in blood pressure in the erect posture, a resting systolic blood pressure below $110 \mathrm{mmHg}$ or a tachycardia of $110 / \mathrm{min}$ were considered indications for urgent blood transfusion. An elective transfusion of packed cells was given if the haemoglobin next day was less than $8 \mathrm{~g} / \mathrm{dl}$. Intravenous cimetidine $0.8 \mathrm{~g}$ daily was used routinely but gastric aspiration, central venous pressure monitoring and sedation were not regularly utilised. Emphasis was placed on early liberal feeding and the use of $B$ and $C$ vitamins, particularly in alcoholic patients.

We found that in a patient thought to have minor bleeding from a non-serious lesion it was reasonable to defer the endoscopy until the next morning. If a gastric ulcer was seen at endoscopy with the stigmata of recent haemorrhage, a visible vessel or blood clot in the base, a surgeon saw the patient to facilitate operative treatment immediately in the event of rebleeding. The ideal was to operate at any hour of the day or night upon a patient with a gastric ulcer who rebled and to start the transfusion at the initiation of surgery. In patients in whom surgery was clearly contraindicated by non-remediable disease endoscopy was often omitted; 38 patients were not endoscoped. The delay between bleeding and endoscopy was less than 24 hours in 100 patients, 24-48 hours in 29 patients and beyond 48 hours in 34. Endoscopy was repeated if the original endoscopy showed a field obscured by blood. Double contrast barium radiology was used on four 
patients where doubt persisted after endoscopy.

\section{Results}

Investigations disclosed a variety of causes of haemorrhage. The major groups were chronic peptic ulcer $42.7 \%$, oesophageal lesions $17.4 \%$, and an acute gastritis/duodenitis/erosion group $11.9 \%$ (Table 1). The overall mortality rate of the series was $9 \%$. Men outnumbered women by about 4 to 1 and the mean age of patients was 52.3 years (range 16-93 years). There were 86 patients with chronic duodenal ulcer and gastric ulcer of whom four were operated upon within 48 hours of a bleeding episode with one postoperative death. Of the remaining 82 patients two died.

\section{BLOOD TRANSFUSION}

The amount of blood transfused varied according to the diagnosis; of the acute mucosal lesion group only four of 24 had a blood transfusion, whereas in the 78 with chronic ulcer as the only lesion 47 were transfused; of the 102, 19 had more than five units. Only five patients had a one unit transfusion. In those who received blood, the mode was six units and only three patients in the peptic lesion group had more than 10 units of blood, excluding intraand postoperative transfusion. In the six patients referred for urgent surgery the preoperative transfusion requirement was $4,6,6,8,9$ and 11 units. Peptic ulcer was not a major contributor to mortality. There were 18 deaths; three in the 78 patients with chronic peptic ulcer as the sole lesion, one in the 14 with two lesions including chronic ulcer and 14 in the 109 patients with non-peptic or unknown diagnosis.

Six patients were referred for urgent surgery, of whom one died. In the 86 patients with chronic duodenal ulcer and gastric ulcer the mortality rate was $3.5 \%$ (Table 2).

Necropsies were obtained in six out of the 18 deaths; of the 12 patients who died without necropsy, four had an endoscopic diagnosis and in one endoscopy failed. Six of the remaining seven had advanced hepatic or cardiac failure and were considered unsalvagable. Of the eight patients who died without an endoscopic or necropsy diagnosis there were only two, aged 72 and 80 years with any possibility of remediable peptic lesion being present.

\section{Discussion}

Case selection plays a major role in the results of acute upper gastrointestinal bleeding. Avery Jones laid the ground rules 35 years ago; all patients whether admitted with bleeding or developing it in hospital should be included in the study group and all deaths in hospital are counted. ${ }^{7}$ We have followed these principles. That the series is representative is shown by a comparison with recent large series from Nottingham ${ }^{2}$ and Melbourne ${ }^{8}$ (Table 1). There is considerable concordance in the diagnostic categories in the three series.

In all three studies the mean age was in the sixth decade. In the current series the mortality rate was $9 \%$ compared with $8.4 \%$ in the series of Dronfield $e t$ $a l^{2}$ but this latter series was limited to those undergoing endoscopy; overall in that series it was $11.8 \%$. In our series 163 patients were endoscoped. Seven $(4.3 \%)$ of these patients subsequently died; of

Table 1 Diagnosis and mortality in this and recent series

\begin{tabular}{|c|c|c|c|}
\hline & \multicolumn{3}{|l|}{ No $(\%)$} \\
\hline & Present series & Dronfield et al ${ }^{2}$ & Sereda et al ${ }^{8}$ \\
\hline Oesophageal lesions Mallory-Weiss, oesophagitis, ulcer, carcinoma & $35(17 \cdot 4)$ & $64(12 \cdot 2)$ & $59(11 \cdot 5)$ \\
\hline Oesophageal varices & $16(8)$ & $10(1 \cdot 9)$ & $43(8 \cdot 4)$ \\
\hline Gastritis, duodenitis, erosion & $24(11 \cdot 9)$ & $35(6 \cdot 7)$ & $102(19 \cdot 9)$ \\
\hline Gastric ulcer & $29(14 \cdot 4)$ & $134(25 \cdot 5)$ & $47(9 \cdot 2)$ \\
\hline Duodenal ulcer & $34(16 \cdot 9)$ & $122(23 \cdot 2)$ & $143(27 \cdot 9)$ \\
\hline Duodenal ulcer and gastric ulcer & $23(11 \cdot 4)$ & - & - \\
\hline Stomal ulcer & $6(3)$ & - & $10(1.9)$ \\
\hline Carcinoma of stomach & $2(1)$ & $16(3)$ & $7(1 \cdot 4)$ \\
\hline Carcinoma of pancreas & - & $1(2)$ & - \\
\hline Investigation incomplete & $26(12 \cdot 9)$ & - & $2(0 \cdot 4)$ \\
\hline Endoscoped: no lesions found & $8(4)$ & $144(27 \cdot 4)$ & $100(9 \cdot 4)$ \\
\hline Total patients & $201^{*}$ & 526 & 513 \\
\hline Mean age & $52 \cdot 3$ & $59 \cdot 2$ & $55+$ \\
\hline Mortality rate \% & $9 \cdot 0$ & $8 \cdot 4+$ & $8 \cdot 8$ \\
\hline
\end{tabular}

* Some patients had multiple lesions.

$\dagger 11.8 \%$ including deaths in excluded patients. 
Table 2 Gastric ulcer and duodenal ulcer results in this and other series

\begin{tabular}{|c|c|c|c|c|}
\hline & Present series $1980-81$ & Previous series 1964-74 & Vellacott et al ${ }^{3}$ & Hunt et al ${ }^{9}$ \\
\hline All duodenal ulcer and gastric ulcer & 86 & 309 & 908 & 380 \\
\hline Urgent surgery & 4 & 31 & 245 & 163 \\
\hline Surgery rate $\%$ & $5 \cdot 1$ & 10 & 27 & 43 \\
\hline Operative deaths & 1 & 1 & 54 & 17 \\
\hline Surgical mortality rate $\%$ & 25 & $3 \cdot 2$ & 22 & $10 \cdot 4$ \\
\hline All deaths & 3 & 15 & 102 & 23 \\
\hline Mortality rate (SE) \% & $3 \cdot 5(2 \cdot 0)$ & $4 \cdot 9(1 \cdot 2)$ & $11 \cdot 2(1 \cdot 0)$ & $6 \cdot 1(1 \cdot 2)$ \\
\hline \multicolumn{5}{|l|}{ Blood transfusion } \\
\hline Rate: $>4$ units & - & $48(15 \cdot 5 \%)$ & - & - \\
\hline$>5$ units & $16(18 \cdot 6 \%)$ & - & $292(32 \cdot 2 \%)^{*}$ & - \\
\hline$>6$ units & - & $25(8 \cdot 1 \%)$ & - & - \\
\hline$<10 \mathrm{~g} / \mathrm{dl}$ & $64 / 92(69 \cdot 6 \%)$ & $142 / 309(46 \%)$ & $614 / 908(67 \cdot 6 \%)$ & - \\
\hline
\end{tabular}

* Appears to approximate to surgery rate.

the 38 not endoscoped, 11 died. The Melbourne group have more recently reported their later experience extending over total of six years ${ }^{9}$ with a highly significant improvement in gastric ulcer mortality figures in the last two years. They utilised a similar protocol throughout with a mortality rate of $7 \%$ in a series of 894 admissions to the haematemesis and melaena unit (Table 2).

In view of the current debate concerning the benefit of aggressive management it is of interest to compare and contrast these three series. We transfused $18.6 \%$ of those with a chronic duodenal ulcer or gastric ulcer with more than four units of blood; $32.2 \%$ of Vellacott's Nottingham series of duodenal ulcer and gastric ulcer patients had more than five units of blood; in the earlier Melbourne series $48.4 \%$ had more than five units. We transferred acute erosive bleeding less than the Melbourne group, two of $24(8 \%)$ patients having four units of blood or more whereas they gave $25 \%$ of such patients this much. ${ }^{10}$ It has previously been shown, as Avery Jones had shown 35 years earlier, that ulcer bleeding, using a conservative blood transfusion regime, was episodic and selfterminating in the majority of instances.

The proportion of patients in the present series referred for urgent surgery is low compared with modern practice. Of the six patients, four had chronic gastric ulcer, one had a Mallory-Weiss and one had a vascular anomaly near the cardiooesophageal junction. Partial gastrectomy was carried out on the gastric ulcer patients with one death, and the other two lesions were successfully oversewn. Our surgery rate of $5.1 \%$ for patients with chronic duodenal ulcer or gastric ulcer contrasts with the later Melbourne figure of $42.9 \%$.

An inherent defect in the present study is its relatively small size. We therefore present some of the results of one of us (JMD) using the regimen described during 1964-74 (Table 2). There is a remarkable concordance in the mortality rates and urgent surgery rates, but the transfusion rate is higher in the present series than in the previous one. Comparisons can be made with the Nottingham and Melbourne series.

The mortality rate of chronic duodenal ulcer and gastric ulcer in the combined series was $4.8 \%$ compared with $11.2 \%$ in Nottingham and $6.1 \%$ in Melbourne $(p>0 \cdot 1)$. The mean surgery rate in Newcastle was $8.9 \%$ compared with $27 \%$ in Nottingham and $42.9 \%$ in Melbourne $(p<0.005)$. The surgical mortality rate was $5.7 \%$ in Newcastle compared with $22 \%$ and $10.4 \%$ respectively $(p>0 \cdot 1)$. Comparison of blood transfusion practices was difficult but more than five units of blood were given to approximately one in five of our ulcer patients, to one in three Nottingham patients and to about one in two Melbourne patients. While strict comparison required unavailable data on age composition, Table 1 suggests no gross difference between the Melbourne and Newcastle series in age composition but the Nottingham patients were nearly seven years older.

The Nottingham group, ${ }^{3}$ having compared the results during a period of declining surgical intervention found that a reduction in operation rates had no appreciable effect on mortality, despite the accepted view that early operation is advisable. At least part of the explanation resides in the fact that a minority of deaths occur in those with peptic ulcer alone as the diagnosis. Much more lethal are other bleeding lesions not amendable to surgery such as cirrhosis. At the Edinburgh Royal Infirmary, most deaths in a two year period were not preventable. ${ }^{11}$

The Oxford group in a study of 2149 admissions over a 15 year period found no change in overall mortality rate while the urgent surgery rule declined 
from $23.7 \%$ to $15.3 \% .^{12}$ The Nottingham group have also compared the experience of two hospitals with different surgical policies and found that the mortality rate of bleeding peptic ulcer was higher in the hospital using surgery more often. ${ }^{13}$

The present study, with a mortality rate for bleeding chronic peptic ulcer less than that of other studies utilising more surgery and transfusion suggest that a formal trial of the conservative approach, such as outlined above, is warranted.

We would like to thank Mrs Helen Johnson, SRN who played an essential role in personally collecting data from the patients in this study, also our surgical colleagues, particularly Mr E J Hennessy, played a crucial part in management. Also Miss Robyn Balser and Mrs Louise Pipan who typed numerous revisions.

\section{References}

1 Young AE. Stopping the haemorrhage from peptic ulcers. Br Med J 1982; 284: 530.

2 Dronfield MW, Langman MJS, Atkinson M, et al. Outcome of endoscopy and barium radiography for acute upper gastrointestinal bleeding: controlled trial in 1037 patients. $\mathrm{Br}$ Med J 1982; 284: 545-8.
3 Vellacott KD, Dronfield MW, Atkinson M, Langman MJS. Comparison of surgical and medical management of bleeding peptic ulcers. $\mathrm{Br}$ Med J 1982; 284: 548-50.

4 Duggan JM. Haematemesis and melaena: a survey. Med J Aust 1956; 2: 941-9.

5 Duggan JM. Acute gastrointestinal haemorrhage: prognostic factors on a conservative regime. Med $J$ Aust 1972; 2: 187-93.

6 Ivy AL, Grossman MI, Bachrach MH. Peptic ulcer. London: Churchill, 1950: 937.

7 Jones FA. Haematemesis and melaena with special reference to bleeding peptic ulcer. $\mathrm{Br}$ Med J 1947; 2: 441-6.

8 Sereda S, Lamont L, Hunt P. The experience of a haematemesis and melaena unit. A review of the first 513 consecutive admissions. Med J Aust 1977: 1: 362-6.

9 Hunt PS, Hansky J, Korman MG. Mortality in patient with haematemesis and melaena: a prospective study. Br Med J 1979; 1: 1238-40.

10 Hunt PS, Korman MG, Hansky J, Schmidt GT, Hillman HS. Acute gastric ulceration - a prospective study of incidence and results of management. Aust NZ J Med 1980: 10: 305-8.

11 Logan RFA, Finlayson NDC. Death in acute upper gastrointestinal bleeding. Can endoscopy reduce mortality? Lancet 1976; 1: 1173-4.

12 Schiller KRF, Truelove SC, Williams DG. Haematemesis and melaena with special reference to factors affecting outcome. Br Med J 1970; 1: 7-14.

13 Dronfield MW, Atkinson M, Langman MJS. Effect of different operation policies on mortality from bleeding peptic ulcer. Lancet 1979; 1: 1126-8. 